\title{
Comparative effects of Alpha Tocopherol and Ascorbic Acid on Chronic Stress Induced Neuropeptide Y Derangements
}

\author{
Saadia Zainab ${ }^{1}$, Tahir Ahmad Munir ${ }^{2}$, Anjum Ilahi ${ }^{3,4}$, Adnan Saleem Khan ${ }^{5}$ \\ ${ }^{1}$ Assistant Professor, Department of Physiology, Al-Nafees Medical College, Islamabad \\ 2Professor, Department of Physiology, Mohi-ud-Din Islamic Medical College, Mirpur AJK \\ ${ }^{3}$ Associate Professor, Department of Medicine, Al-Nafees Medical College, Islamabad \\ ${ }^{4} \mathrm{Head}$, Department of Cardiology, Al-Nafees Medical College, Islamabad \\ ${ }^{5}$ Registrar, Department of Cardiology, Al-Nafees Medical College, Islamabad
}

\begin{abstract}
A B STRACT
Background: Chronic stress decreases resilience of the body mainly due to hormonal imbalance. Neuropeptide $Y$-ergic system is abnormally regulated in chronic stress due to reduction-oxidation imbalance. The antioxidants such as alpha-tocopherol and ascorbic acid reduce this imbalance with positive effect on neuropeptide $Y$ synthesis and release. This study was aimed to compare the protective effects of alpha-tocopherol and ascorbic acid on plasma neuropeptide $Y$ levels in chronic stress.

Material and Methods: This quasi-experimental study was done at Al-Nafees Medical College in collaboration with National Institute of Health Islamabad from January 2015 to January 2016 after taking institutional approval. Sixty male Sprague Dawley rats were obtained and divided equally into four groups; group I (control), group II (restraint stress group - chronic restraint stress six hours daily for 28 days), group III (restraint stress + alpha-tocopherol $50 \mathrm{mg} / \mathrm{kg}$ body weight /day), and group IV (restraint stress + ascorbic acid 100mg / kg body weight /day). Cardiac puncture was done to obtain blood for biochemical analysis.

Results: A significant decrease in plasma neuropeptide Y levels was seen in group II compared to group I, group III and group IV. However, alpha-tocopherol administration in group III showed positive effects on maintenance of plasma neuropeptide $Y$ concentration with better $p$ trend than that of ascorbic acid supplementation in group IV.

Conclusion(s): Alpha-tocopherol supplementation has more potent effect than that of ascorbic acid on chronic restraint stress induced derangements in neuropeptide $Y$ levels. It leads to less imbalance in neuropeptide $Y$ levels during chronic stress.

Key words: Ascorbic Acid, Alpha-Tocopherol, Chronic Stress, Neuropeptide $Y$

Authors' Contribution: Correspondence: Article info:

1-3Conception: Literature research; Saadia Zainab

Received: April 17, 2019

manuscript design and drafting; ${ }^{4}$ Critical Email:drsaadiakmu7@gmail.com

Accepted: March 17, 2020

analysis and manuscript review; Data

analysis; Manuscript Editing

Cite this article. Zainab S, Munir TA, Anjum-Ilahi, Khan AS. Comparative Effects of Alpha

Tocopherol and Ascorbic Acid on Chronic Stress Induced Neuropeptide Y Derangements. J

Islamabad Med Dental Coll.2020; 9(1): 35-41. Doi: 10.35787/jimdc.v9i1.332

Funding Source: Nil

Conflict of Interest: Nil

\section{Introduction}

Stress disturbs body homeostasis and activates several adaptive responses. Good stress, known as Eustress, is associated with positive motivational attitude while bad stress or distress is linked with

body dysfunction and aversive behavioral changes in organism such as escape or avoidance of stressor which endanger the body. ${ }^{1}$ Chronic stressors like prolonged illness, poverty, unemployment and
\end{abstract}


several other factors leads to repetitive stress and cause body dysfunction. Stress affects immune system by activating sympathetic-adrenalmedullary system and the hypothalamic-pituitaryadrenal system that alter the byproducts of oxygen metabolism. $^{2}$

Neuropeptide $Y$ (NPY) is synthesized in many are as of brain including arcuate nucleus, locus coeruleus, nucleus tractus solitarii and septo-hippocampal nucleus and affects stress-related changes in emotional behavior and feeding. The stressrelieving, anxiolytic and the neuro-protective properties of NPY enables the body to cope with stressful conditions. The rate of NPY synthesis depends on the type and duration of stress exposure. Stress, also contributes to and results from, neurodegenerative diseases such as Alzheimer's, Parkinson's and Huntington's diseas es but stress response with normal hormonal milieu has a neuroprotective role.

NPY functions through stimulation of $\mathrm{Y} 1, \mathrm{Y} 2, \mathrm{Y} 4$ and $Y 5$ receptors, counteracts the biological actions of corticotropin releasing hormone and also exerts anxiolytic effects. A research showed that NPY knockout mice were more anxious compared to healthy controls. ${ }^{3}$ An increased NPY concentration in brain and plasma is also seen in inflammatory visceral stress of crohn's disease and ulcerative colitis. A negative correlation between behavioral disruption and cerebral NPY expression is seen in post-traumatic stress disorder in animal studies. ${ }^{4}$

Overstimulation of stress hormones like catecholamine, cortisol and arginine vasopressin tend to increase metabolism and formation of reactive oxygen species (ROS) through metabolic oxidative phosphorylation resulting in a disturbance in the reduction-oxidation homeostasis. ${ }^{5}$ NPY lessens the effects of these stress hormones and normalizes body functions.
Alpha-tocopherol (AT) commonly known as vitam in $E$, is a low-molecular-weight, lipid-soluble, chainbreaking antioxidant, located in tissue membranes. It prevents lipid peroxidation of membranes by interfering with the proliferation of lipid radicals and is capable of scavenging ROS. ${ }^{6}$

Ascorbic acid (AA) or vitamin C is a hydrophilic compound, present in cytosol and extracellular fluid, either in reduced or oxidized forms, has the ability to act as a reducing agent or detoxifies various oxygen radicals in vivo. The antioxidant activity involves its conversion to oxidized form (dehydro-ascorbic acid) by donating two electrons to ROS, and helps in recycling tocopherol. ${ }^{7}$ So, AT and $A A$ antioxidants, are thought to prevent stress induced damage and work with endogenous antioxidants enzyme systems to decrease oxidative stress and widespread oxidative damage. Although international literature points out the interaction of AT and AA with NPY-ergic system, scarcity of the data in our country urged us to do the current study.

In this study the objective was to compare the stabilizing effect of antioxidants AT and AA on plasma NPY levels in oxidative stress caused by prolonged restraint of experimental animals.

\section{Material and Methods}

This quasi-experimental study was done at AlNafees Medical College (ANMC) and Hospital Islamabad in collaboration with National Institute of Health (NIH) Islamabad after approval from the Institutional Review Board of ANMC (letter number: F.2/IUIC-ANMC/EC-58/2015). Total duration of the study was one year from January 2015 to January 2016. Sixty adult male Sprague Dawley rats were obtained from National Institute of Health Islamabad. They were ere equally divided into four groups, with 15 rats in each group by convenient sampling technique. The mean body weight was $275 \pm 25 \mathrm{gm}$. Sample size was calculated 
with $95 \%$ confidence interval, power of 80 and effect size by open epi calculator.

Grouping was done as follows: Group I: Control, Group II: Restraint stress (keeping rats in mesh wire restrainer), Group III: Restraint stress + Alpha tocopherol - $50 \mathrm{mg} / \mathrm{kg}$ body weight $/$ day by gavage $)^{8}$ and Group IV: Restraint stress + Ascorbic acid (100 mg/kg body weight/day by gavage). ${ }^{9}$

Rats were kept in stainless steel cages in a humidity and temperature-controlled room $\left(22 \pm 2^{\circ} \mathrm{C}\right)$ on a 12:12-h light-dark cycle and handled for 1 week before the start of the experiment.

Stress was induced in group II rats through food deprivation and they were immobilized by keeping them individually in wire mesh restrainer for 6 hours/ day $\times 28$ days. ${ }^{10}$ Group III was exposed to restraint stress and supplemented with AT $50 \mathrm{mg} / \mathrm{kg}$ body weight /day orally by gavage. After induction of restraint stress, group IV was supplemented with AA $100 \mathrm{mg} / \mathrm{kg}$ body weight /day orally by gavage after mixing in $2 \mathrm{ml}$ drinking water. Doses of AT and AA both were calculated on the basis of their antioxidant effects which can be achieved by selection of the oxidative stress dose in rats. Control group and restraint group were given simple drinking water by gavage.

After induction of chronic restraint stress for a period of 28 consecutive days, 5 rats at a time were placed in closed chamber with ether-soaked cotton. It took 5-6 minutes for rats to get anesthetized. Cardiac puncture was done with 23-gauge cardiac puncture needle and $4 \mathrm{cc}$ blood samples were taken from each rat. ${ }^{11}$ The blood samples were transferred to separate vacutainers containing anticoagulant EDTA for plasma. The samples were centrifuged at $3000 \mathrm{rpm}$ for 15 minutes and transferred to labelled Eppendorf tubes. Plasma was stored at $-20^{\circ} \mathrm{C}$ for NPY, ELISA biochemical analysis.
Means $( \pm S D)$ of plasma NPY levels in different groups were calculated. The difference in means of plasma NPY levels between and withing the groups was calculated by One-way ANOVA and Post hoc Tuckey test. P-value $>0.05$ was taken as statistically significant.

\section{Results}

The results showed that plasma NPY levels in control group I ranged between $0.502-0.690 \mathrm{ng} / \mathrm{ml}$ with a mean $\pm S D \quad 0.619 \pm 0.05$, while in restraint stress group II, plasma NPY levels ranges between $0.221-0.513 \mathrm{ng} / \mathrm{ml}$ with a mean $\pm \mathrm{SD}$ value of $0.357 \pm$ 0.07 .9 (Table I). The plasma NPY levels of group III restraint supplemented with alpha-tocopherol $(50 \mathrm{mg} / \mathrm{kg} /$ body weight $/$ day) ranges between 0.513 $0.682 \mathrm{ng} / \mathrm{ml}$ with a mean \pm SD value of $0.570 \pm 0.05$ $\mathrm{ng} / \mathrm{ml}$ while NPY levels in group IV, restraint with ascorbic acid $(100 \mathrm{mg} / \mathrm{kg} /$ body weight/day) ranges between $0.465-0.643 \mathrm{ng} / \mathrm{ml}$ with a mean $\pm S D$ value of $0.554 \pm 0.04 \mathrm{ng} / \mathrm{ml}$ (Table I).

A linear relationship between NPY absorbance against standard concentrations was obtained. (Figure 1) This standard curve was plotted by presenting the known concentrations of standard on the log scale ( $x$-axis) and its corresponding corrected absorbance on $y$-axis. The value of $y$ intersect was used to calculate the concentration of samples.

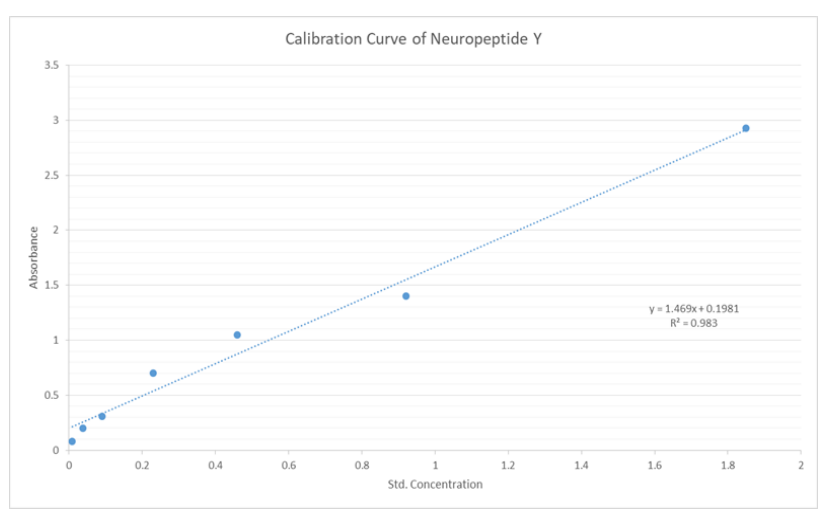

Figure 1: Calibration curve between standard concentration and absorbance of Neuropeptide-Y 


\begin{tabular}{|c|l|l|l|c|c|}
\hline \multicolumn{7}{|c|}{ Table I: Comparison of Mean \pm SD of plasma Neuropeptide Y in different groups. } \\
\hline Variable & \multicolumn{2}{|c|}{ Groups } & Mean \pm SD & $\mathbf{9 5 \%}$ Cl & $\boldsymbol{P}$-value \\
\hline \multirow{4}{*}{} & \multirow{3}{*}{ NPY } & II & $0.357 \pm 0.07$ & $0.2120-0.3148$ & 0.001 \\
\cline { 2 - 6 } & $0.619 \pm 0.05$ & III & $0.570 \pm 0.05$ & $0.0108-0.0904$ & 0.212 \\
\cline { 2 - 6 } & II & IV & $0.554 \pm 0.04$ & $0.0273-0.1035$ & 0.047 \\
\cline { 2 - 6 } & $0.357 \pm 0.07$ & III & $0.570 \pm 0.05$ & $-0.2618--0.1638$ & 0.001 \\
\cline { 2 - 6 } & III & IV & $0.554 \pm 0.04$ & $-0.2454--0.1505$ & 0.001 \\
& $0.570 \pm 0.05$ & IV & $0.554 \pm 0.04$ & $-0.0201-0.0498$ & 0.961 \\
\hline
\end{tabular}

\begin{tabular}{|c|l|c|c|c|c|c|}
\hline \multicolumn{2}{|l|}{ Table II. One Way ANOVA for NPY between and within the Groups } \\
\hline \multicolumn{2}{|c|}{} & Sum of Squares & Df & Mean Square & F & P -value \\
\hline \multirow{2}{*}{ NPY } & Between Groups & .671 & 4 & .168 & 41.219 & .000 \\
\cline { 2 - 8 } & Within Groups & .285 & 70 & .004 & - & - \\
\hline
\end{tabular}

A statistically significant difference was noticed when NPY values were compared between group I and II, and I and IV, however, the values was found to be non-significant $(P-0.212)$ when control group was compared with group III (Table I).

The NPY levels were also found statistically significant $(P<0.05)$ when group II was compared with group III. Same trend of significant difference $(P<0.05)$ was noted between group II and group IV. Difference was non-significant when group III and group IV were compared ( $P$-0.916). A statistically significant value $(P<0.05)$ was seen between the groups and within the groups (Table II).

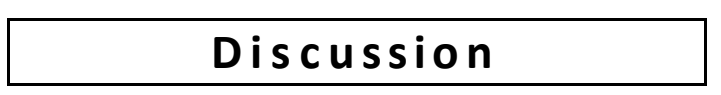

Our results showed an increased plasma concentration of NPY in control group compared to restraint group. These results are consistent with Grisé et al $^{12}$ who showed increased plasma NPY levels in control group compared to restraint group, while Hassan et $\mathrm{al}^{13}$ showed same results in a study conducted on mice. Our results are not in agreement with Zhang et $\mathrm{al}^{14}$ who showed decreased NPY levels in control group, the difference may be due to use of rodent female rat strain and use of different kits. Eskandarzade $\mathrm{N}$ et $\mathrm{al}^{15}$ showed same plasma NPY level of control group and in starved rats.
Restraint stress in the form of food deprivation and immobilization was induced in rats of group II. Data of group II showed low plasma NPY levels than that of control group I and other experimental groups III, IV. The results are similar with Daubert et al ${ }^{16}$ who showed decreased plasma NPY levels in rats with chronic restrained stress. Results shown by Kuo et $\mathrm{al}^{17}$ were different from our study, who concluded that chronic restraint stress raises plasma NPY levels. The reason of difference could be lesser duration of stress exposure.

Our results showed low levels of plasma NPY in restraint stress group given AT compared to control group I. A study conducted by Salehi et al ${ }^{18}$ showed similar results that used high fat diet to induce oxidative stress that was later ameliorated by administration of AT and AA in combination. In this study combination of two antioxidants was used because AA potentiates the action of AT when used in combination, by recycling the radical of AT to protect the cell membranes from lipid peroxidation caused by accumulation of ROS. Thereby antioxidants reduce neuronal toxicity by sparing action on neuronal cell membranes and secretion. ${ }^{18}$ Similar results were noticed by Hounsom et al ${ }^{19}$ who found depleted plasma NPY levels in rats deficient in alpha-tocopherol compared to control group. Another study conducted on mice given AT 
in fish oil showed improved cognitive functions and maintenance of NPY mRNA in the brain. ${ }^{20}$

AT along with angiotensin converting enzyme inhibitors decrease the formation of ROS in intima and media of aortic walls in mice with atheroscle rosis. Accumulation of ROS is a feature of both atherosclerosis and high concentrations of angiotensin II in vasculature. ${ }^{21}$ AT increases the permeability of blood brain barrier in streptozotocin induced convulsions in albino rats and spare the action on NPY release to attain the anticonvulsant effect of NPY. ${ }^{22} \mathrm{AT}$, in any form, inhibits oxidation of low density lipoproteins and decreases phenomenon of thromboembolism and clot formation and hence decreases heart attacks. When it is given in combination with ascorbic acid (AA) and carotenoids provides safer and effective results. ${ }^{23}$

In our study ascorbic acid (AA) supplementation given to rats exposed to restraint stress showed decreased NPY plasma levels compared to control group. The results are in agreement with Simonneaux et $\mathrm{al}^{24}$ who showed potentiating effects of NPY on rhythmic pineal gland secretion by $A A$ on rodent model.

Another study conducted by Dixit et $\mathrm{al}^{25}$ have established link between AA deficiency, impaired cognition and oxidative stress showing membrane stabilizing effects of AA in oxidative stress. The intracerebroventricular administration of AA leads to markedly decreased food intake in rats by interfering with actions of dopamine and NPY. ${ }^{26}$

AT being lipophilic, acts readily on cell membranes and stops lipid peroxidation and quench free radicals potently. However, hydrophilic AA target cytosol and plasma alone and in synergism with AT to mop ROS directly. ${ }^{27}$ Bartali et al showed more potent antioxidant ability of AT for free radical scavenging as compared to AA by keeping membrane integrity and intact secretory activity of
NPY. It has been determined that deficiency of AT with aging leads to a decline in physical function. ${ }^{28}$

Present study showed statistically significant decline in NPY plasma levels after induction of chronic stress. Comparable results of NPY plasma levels of control group and experimental groups with supplementation of AT and AA were obtained. Although statistically insignificant results were obtained between the groups supplemented with AT and AA, but $p$ trend showed better maintenance of NPY levels with AT supplementation.

Limitation: Biochemical analysis could not be done in duplicate due to financial and time constraint.

\section{Conclusion}

Alpha-tocopherol supplementation may exert more beneficial effects than ascorbic acid on chronic restraint induced oxidative stress and derangements in Neuropeptide Y levels.

\section{Recommendation}

Mechanism of action of NPY at receptor level needs to be worked out. Effects of antioxidants on other stress hormones like glutamate and gamma aminobutyric acid can be studied

\section{References}

1. Kozusznik MW, Rodríguez I, Peiró JM. Eustress and distress climates in teams: Patterns and outcomes. International Journal of Stress Management 2015; 22(1): 1-23. Doi: 10.1037/a0038581

2. Srivastava KK, Kumar R. Stress, oxidative injury and disease. Indian J. Clin. Biochem. 2015; 30(1): 3-10. Doi: 10.1007/s12291-014-0441-5

3. Reichmann F, Holzer P. Neuropeptide Y: a stressful review. Neuropeptides. 2016; 55: 99-109. Doi: 10.1016/j.npep.2015.09.008

4. Holzer P, Farzi A, Hassan AM, Zenz G, Jačan A, Reichmann $F$. Visceral inflammation and immune activation stress the brain. Front Immunol. 2017; 8: 1613. Doi: 10.3389/fimmu.2017.01613

5. Wood SK, Bhatnagar S. Resilience to the effects of social stress: Evidence from clinical and preclinical studies on the role of coping strategies. Neurobiol 
Stress. 2015; 1: 164-73. Doi: 10.1016/j.ynstr.2014.11.002

6. Chen AY, Lü JM, Yao Q, Chen C. Entacapone is an Antioxidant More Potent than Vitamin $\mathrm{C}$ and Vitamin E for Scavenging of Hypochlorous Acid and Peroxynitrite, and the Inhibition of Oxidative StressInduced Cell Death. Med Sci Monit 2016; 22: 687. Doi: $10.12659 / \mathrm{msm} .896462$

7. Bursać-Mitrović $M$, Milovanović $D R$, Mitić $R$, Jovanović D, Sovrlić $M$, Vasiljević $P$ et al. Effects of Lascorbic acid and alpha-tocopherol on biochemical parameters of swimming-induced oxidative stress in serum of guinea pigs. Afr J Tradit Complement Altern Med. 2016; 13(4): 29-33. Doi: 10.21010/ajtcam.v13i4.5

8. Ghorbel I, Elwej A, Fendri N, Mnif H, Jamoussi K, Boudawara T, Grati Kamoun N, Zeghal N. Olive oil abrogates acrylamide induced nephrotoxicity by modulating biochemical and histological changes in rats. Ren Fail. 2017; 39(1): 236-45. Doi: 10.1080/0886022X.2016.1256320

9. Ahmed OM, Ashour MB, Fahim HI, Ahmed NA. Citrus limon and paradisi fruit peel hydroethanolic extracts prevent the progress of complete freund's adjuvant-induced arthritis in male wistar rats. Adv Anim Vet Sci. 2018; 6(10): 443-55.

10. Lodhi GM, Latif R, Hussain MM, Naveed AK, Aslam M. Effect of ascorbic acid and alpha tocopherol supplementation on acute restraint stress induced changes in testosterone, corticosterone and nor epinephrine levels in male Sprague Dawley rats. J Ayub Med Coll Abbottabad. 2014; 26(1): 7-11. PMID: 25358206

11. Kumar M, Dandapat S, Sinha MP, Kumar A, Raipat BS. Different blood collection methods from rats: $A$ review. Balneo Res. J. 2017; 8(2): 46-50. Doi: 10.12680/balneo.2017.141

12. Grisé KN, Olver TD, McDonald MW, Dey A, Jiang $M$, Lacefield JC, et al. High Intensity Aerobic Exercise Training Improves Deficits of Cardiovascular Autonomic Function in a Rat Model of Type 1 Diabetes Mellitus with Moderate Hyperglycemia. J Diabetes Res. 2016; 2016. 8164518e. Doi: 10.1155/2016/8164518

13. Hassan A, Jain P, Reichmann F, Mayerhofer R, Farzi A, Schuligoi $R$, et al. Repeated predictable stress causes resilience against colitis-induced behavioral changes in mice. Front Behav Neurosci. 2014; 8: 386-90. Doi: 10.3389/fnbeh.2014.00386

14. Zhang P, Qi YX, Yao QP, Chen XH, Wang GL, Shen BR, et al. Neuropeptide $Y$ stimulates proliferation and migration of vascular smooth muscle cells from pregnancy hypertensive rats via Y1 and Y5 receptors. PloS one. 2015; 10(7): e0131124. Doi: 10.1371/journal.pone.0131124

15. Eskandarzade $N$, Saeb $M$, Nazifi S, Saeb $S$, Kazemipour N, Ansari-Lari M. The effect of longterm starvation on galanin, leptin, thyroid hormones, insulin, prolactin, growth hormone, ghrelin and factors involved in energy metabolism in adult goats. J Fac Vet Med Istanbul Univ. 2015; 41: 143-50.

16. Daubert DL, Looney BM, Clifton RR, Cho JN, Scheuer DA. Elevated corticosterone in the dorsal hindbrain increases plasma norepinephrine and neuropeptide $Y$, and recruits a vasopressin response to stress. Am J Physiol Regul Integr Comp Physiol. 2014; 307(2): R212-24. Doi: 10.1152/ajpregu.00326.2013

17. Kuo LE, Czarnecka M, Kitlinska JB, Tilan JU, Kvetňanský R, Zukowska Z. Chronic stress, combined with a high-fat/high-sugar diet, shifts sympathetic signaling toward neuropeptide $Y$ and leads to obesity and the metabolic syndrome. Ann N Y Acad Sci. 2008; 1148(1): 232-7. Doi: 10.1196/annals.1410.035

18. Salehi I, Saidijam M, Vahidinia AA, Sohrabi M, AsI SS. High Fat Diet-Induced Neurotoxicity Alters Following Vitamin $\mathrm{E}$ and $\mathrm{C}$ Administration in Hippocampus of Male Rats. Gene Cell Tissue. 2017; 4(4): e58383. Doi: 10.5812/gct.58383

19. Hounsom L, Corder R, Patel J, Tomlinson DR. Oxidative stress participates in the breakdown of neuronal phenotype in experimental diabetic neuropathy. Diabetologia. 2001; 44(4): 424-8. Doi: 10.1007/s001250051638

20. Avraham Y, Saidian M, Burston JJ, Mevorach R, Vorobiev L, Magen I, et al. Fish oil promotes survival and protects against cognitive decline in severely undernourished mice by normalizing satiety signals. J Nutr Biochem. 2011; 22(8): 766-76. Doi: 10.1016/j.jnutbio.2010.07.001

21. Abd Alla J, el Faramawy Y, Quitterer U. Microarray gene expression profiling reveals antioxidant-like effects of angiotensin II inhibition in atherosclerosis. Front Physiol. 2013; 4: 148. Doi: 10.3389/fphys.2013.00148

22. Yorulmaz $H$, Seker FB, Oztas B. Effect of vitamin E on blood-brain barrier permeability in aged rats with PTZ-induced convulsions. Neurophysiol. 2011; 42(5): 349-53.

23. Renata M, Masha L, Jose L, Shahab K, Gitanjali M, Mayuree R. Etiologic effects and optimal intakes of foods and nutrients for risk of cardiovascular diseases and diabetes: Systematic reviews and meta-analyses from the Nutrition and Chronic Diseases Expert Group. PLoS One. 2017; 12(4): e0175149. Doi: 10.1371/journal.pone.0175149 
24. Simonneaux V, Ouichou AH, Craft C, Pévet P. Presynaptic and postsynaptic effects of neuropeptide $Y$ in the rat pineal gland. J Neurochem. 1994; 62(6): 2464-71. Doi: 10.1046/j.1471-4159.1994.62062464.x

25. Dixit S, Bernardo A, Walker JM, Kennard JA, Kim GY, Kessler ES, et al. Vitamin C deficiency in the brain impairs cognition, increases amyloid accumulation and deposition, and oxidative stress in App/PSEN1 and normally aging mice. ACS Chem Neurosci. 2015; 6(4): 570-81. Doi: 10.1021/cn500308h

26. Abbasnejad M, Sofiabadi M, Moghimi A, Sadeghian $N$. The effects of intracerebroventricular injection of ascorbic acid on feeding behavior in male rats. J Jahrom Univ Med Sci. 2012; 10(3): 47-50. Doi:10.29252/jmj.10.3.57

27. Forni LG. Metabolic resuscitation in sepsis: could antioxidants be the answer? SIGNA VITAE. 2017; 13(3): 16-19. Doi:10.22514/SV133.062017.2

28. Bartali B, Curto T, Maserejian NN, Araujo AB. Intake of antioxidants and subsequent decline in physical function in a racially/ethnically diverse population. J Nutr Health Aging. 2015; 19(5): 542-7. Doi:10.1007/s12603-015-0449-4 